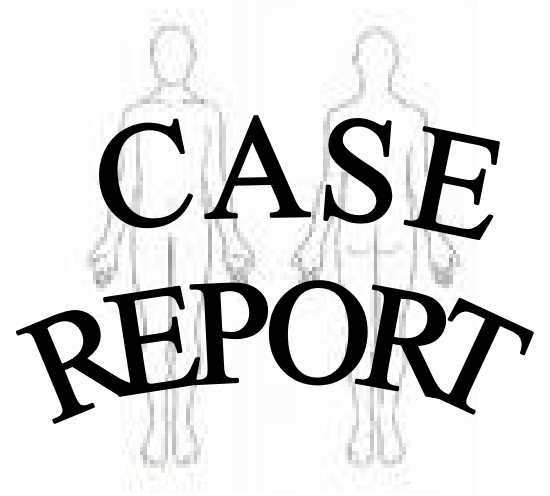

Introduction

West Nile Virus (WNV) belongs to the family Flaviviridae ${ }^{1-4}$ and is related to Japanese encephalitis. ${ }^{4,5}$ The virus usually is spread via the Culex mosquito with humans being an incidental reservoir. ${ }^{4,6}$ It is a febrile illness, which is accompanied by "flu-like" or nonspecific symptoms. Most commonly, people present with myalgias, arthralgias, fever, and lymphadenopathy. More severely, it can present with, but not limited to nuchal rigidity, altered mental status, and personality changes. ${ }^{1,3,4}$

WNV was identified first in 1937 in Uganda and since has been identified in parts of the Middle East and Asia. ${ }^{1,2,4}$ In the 1950s, it was seen in Egypt and Israel, and moved West, causing a major outbreak of encephalitis in Romania in the 1990s. ${ }^{3,4}$ It also has been seen in other parts of Europe and Asia including, but not limited to, France, Italy, and India. ${ }^{4}$ Before 1999, only four arboviruses had been endemic in the United States: St. Louis encephalitis, eastern equine encephalitis, western equine encephalitis, and La Crosse encephalitis. ${ }^{2} \mathrm{WNV}$ first was identified in the US during an outbreak in New York in 1999. ${ }^{2,7,8}$ It initially was identified in Kansas in 2002. ${ }^{9}$

A case of proven West Nile encephalitis is reported to illustrate the presentation of the viral encephalitis and to remind clinicians to keep it on their differential diagnosis.

\section{West Nile Encephalitis}

\author{
Sapna A. Shah-Haque, M.D., M.B.A., \\ Elizabeth Rinehart, MS4, \\ Boutros El-Haddad, M.D. \\ University of Kansas \\ School of Medicine-Wichita \\ Department of Internal Medicine
}

\section{Case Report}

A 30-year-old Caucasian male known to have a history of seasonal allergy and wellcontrolled asthma was transferred to the hospital from an outlying facility because of increased confusion and agitation. One week prior to presentation, the patient complained of nonspecific myalgias that were attributed to recent strenuous outdoor activity or possibly the onset of a flu-like illness.

These symptoms were followed by a rash on his neck that was attributed to sun exposure and skin irritation. Over the next four days, the rash spread from the neck to include his back and arms. A week later, he reported a fever of $102^{\circ}$ Fahrenheit, along with recurrent nausea and vomiting, new onset of lethargy, and generalized weakness. He was taken to the local emergency room for further evaluation and hospitalized. Due to increased agitation, the patient was transferred to our tertiary facility.

During transport, the patient was agitated and required sedation. He was obtunded and intubated to protect his airway. Supportive care was administered.

On physical examination, the patient was afebrile. He was responsive to pain although intubated and sedated. He did not exemplify nuchal rigidity. Both Kernig and Brudzinski signs were absent. He underwent a lumbar puncture and was started on doxycycline to cover for suspected tick-borne illness due to his history of outdoor hobbies and febrile illness with rash. 
Analysis of cerebrospinal fluid (CSF) showed pleocytosis with $585 / \mathrm{mm}^{3}$ leukocytes of which $65 \%$ were lymphocytes and $29 \%$ were neutrophils. CSF glucose was within normal range at $54 \mathrm{mg} / \mathrm{dl}$, but protein was elevated at $119 \mathrm{mg} / \mathrm{dl}$, with serum glucose of $88 \mathrm{mg} / \mathrm{dL}$ and serum protein of $7.3 \mathrm{~g} / \mathrm{dL}$. Polymerase chain reaction (PCR) for Herpes Simplex Virus (HSV) and enteroviruses were negative. Human Immunodeficiency Virus (HIV) serology was negative.

Computed tomography (CT) without contrast and magnetic resonance imaging (MRI) with and without contrast showed normal anatomy. Immunoglobulin $\mathrm{G}$ (IgG) and immunoglobulin $\mathrm{M}(\operatorname{IgM})$ on the cerebrospinal fluid for West Nile virus were positive at a 1:2 dilution. Serum IgG and IgM for West Nile were positive at greater than 1:320 dilutions. The diagnosis of West Nile encephalitis was confirmed.

An infectious disease specialist was consulted. Doxycycline was discontinued and supportive care was recommended. The patient was extubated, but continued to be agitated and confused. The patient's agitation completely resolved prior to discharge, and he began to recall details of his illness prior to hospitalization. Although his confusion resolved, he had some difficulty recalling short term memory items. With the help of physical and occupational therapy, the patient began to regain strength. He was dismissed home with outpatient physical therapy to assist him with residual weakness.

\section{Discussion}

This case of WNV infection was transmitted more than likely via a mosquito, as human to human transmission is very rare, and the patient had no history of recent blood transfusion. ${ }^{10}$ Since 2003, the incidence of WNV has decreased. In the US, 386 cases of neuro-invasive WNV were reported, spanning from May through
October 2009. ${ }^{11}$ From 2006-2008, the median number of confirmed cases of neuroinvasive WNV in Kansas was five per year. ${ }^{10}$ In each of 2009 and 2010 , there were three neuro-invasive cases in Kansas. ${ }^{12}$

Most individuals who encounter WNV present with flu-like symptoms and usually have unsuspected, hence unreported, cases. Less than $1 \%$ of reported cases will have neurological manifestations of the virus, ${ }^{4}$ such as acute flaccid paralysis, headache, dyskinesias, confusion, agitation, or obtundation. ${ }^{4,13-16}$ Risk factors for more severe presentation of WNV include having comorbidities (i.e., diabetes mellitus or hypertension), prolonged steroid use, age 50 years or older, and immunocompromise. ${ }^{13,15}$ Initially presenting with severe illness does not correlate with poor prognosis. ${ }^{14}$ The diagnosis of WNV can be made with clinical suspicion and detection of $\operatorname{IgM}$ to the virus on CSF, serum, or tissue. ${ }^{13,15,16}$ The criteria to make the diagnosis of $\mathrm{WN}$ encephalitis are outlined in Table 1.

Differentiating $\mathrm{WN}$ encephalitis from WN meningitis can be challenging. Diagnostic criteria for both include fever, leukocytosis, and pleocytosis on CSF. ${ }^{14}$ However, with WN meningitis, the patient may exhibit nuchal rigidity, phonophobia, photophobia, and/or Kernig or Brudzinski sign. In addition, imaging may show findings consistent with acute meningeal inflammation, however, findings on imaging are not necessary to make the diagnosis.

In contrast with $\mathrm{WN}$ encephalitis, the patient may not show meningeal signs. The patient may show confusion, agitation, obtundation, irritability or, personality changes. ${ }^{14}$ Imaging of WN encephalitis may show acute inflammation without involving the meninges, suggesting a meningoencephalitis. CT of the head rarely exhibits clinical findings, whereas an MRI may show enhancement of the periventricular area or the leptomeninges. ${ }^{15,16}$ 
Table 1. The criteria to make the diagnosis of WN encephalitis. ${ }^{13}$

\section{Febrile illness with neurological manifestations (headache, aseptic meningitis, myelitis) plus at least one of the following:}

1. Isolation of WNV from tissue, blood, CSF, or other body fluids.

2. Demonstration of WN viral antigen or genomic sequence in tissue, blood, CSF, or other body fluids.

3. Demonstration of WN IgM antibody in acute CSF sampling using MAC-ELISA.

4. Demonstration of 4-fold change in PRNT antibody titer to WNV in paired, appropriately timed acute and convalescent serum samples.

5. Demonstration of WNV-specific IgM (by MAC-ELISA) and IgG (by ELISA or HI antibody titer, confirmed by PRNT) in a single serum sample.

CSF analysis in WN encephalitis may show pleocytosis with a predominance of lymphocytes that rarely exceeds 100 cells/microliter. Protein may be elevated and glucose usually is within normal range. ${ }^{16}$ Our patient's CSF analysis showed a lymphocyte predominant pleocytosis, but the cell count was greater than 100 cells/microliter. Protein was elevated and glucose was normal.

Unlike other encephalitic viruses, WN encephalitis patients usually have a good prognosis and do not manifest long-term side effects, though it may take time to recover with rehabilitation. ${ }^{4,14}$ The treatment of WN encephalitis usually is supportive care. Ribavirin has been used, but did not show any clinical significant benefit., ${ }^{4,13}$ Interferon alpha-2b has shown some promise in animal models, particularly when

\section{References}

${ }^{1}$ Pourrut X, Nkoghé D, Paweska J, Leroy E. First serological evidence of West Nile virus in human rural populations of Gabon. Virology Journal 2010; 7:132. PMID: 20565765.

2 Peterson A, Robbins A, Restifo R, Howell J, Nasci R. Predictable ecology and geography of West Nile Virus transmission in the central United States. J Vector Ecol 2008; 33(2): 342-352. PMID: 19263855. combined with ribavirin. In regard to human treatment, further research is warranted. ${ }^{17}$

\section{Conclusions}

In conclusion, during the warmer months of the year, WNV should be included in the differential diagnoses when a patient presents with flu-like symptoms, especially in those with neurological changes. Our patient presented with nonspecific flu-like symptoms followed by generalized weakness and increased agitation. In light of the patient's neurological manifestations and other reported cases of WNV within the patient's state of residence, suspicion of WNV was high. WN IgM was isolated in the CSF as well as in the serum. The patient continued to improve and required only outpatient physical therapy on dismissal.

3 Tsai TF, Popovici F, Cernescu C, Campbell GL, Nedelcu NI. West Nile encephalitis epidemic in southeastern Romania. Lancet 1998; 352(9130):767771. PMID: 9737281.

${ }^{4}$ Klein C, Kimiagar I, Pollak L. Neurological features of West Nile virus infection during the 2000 outbreak in a regional hospital in Israel. J Neurol Sci 2002; 200(1-2):63-66. PMID: 12127678. 
5 Hua RH, Chen NS, Qin CF, et al. Identification and characterization of a virus-specific continuous B-cell epitope on the $\operatorname{PrM} / \mathrm{M}$ protein of Japanese Encephalitis Virus: Potential application in the detection of antibodies to distinguish Japanese Encephalitis Virus infection from West Nile Virus and Dengue Virus infections. Virol J 2010; 7:249. PMID: 20858291.

${ }^{6}$ Komar N. West Nile viral encephalitis. Rev Sci Tech 2000; 19(1):166-176. PMID: 11189714.

7 Sampson BA, Armbrustmacher V. West Nile encephalitis: The neuropathology of four fatalities. Ann NY Acad Sci 2006; 951:172-178. PMID: 11797775.

${ }^{8}$ Weiss D, Carr D, Kellachan J, et al. Clinical Findings of West Nile virus infection in hospitalized patients, New York and New Jersey, 2000. Emerg Infect Dis 2001; 7(4):654-658. PMID: 11589170.

${ }^{9}$ Harrison BA, Whitt PB, Roberts LF, et al. Rapid assessment of mosquitoes and arbovirus activity after floods in southeastern Kansas, 2007. J Am Mosq Control Assoc 2009; 25(3):265-271. PMID: 1985 2215.

${ }^{10}$ Kansas Department of Health and Environment. 2009 Arboviral Disease. Available at: http://www.kdheks.gov/epi/ download/disease_summary/2009/Section I/arboviral09all.pdf. Accessed May 23, 2011 .
${ }^{11}$ US Centers for Disease Control and Prevention. Morbidity and Mortality Weekly Report Summary of Notifiable DiseasesUnited States 2009. May 13, 2011. Available at: http://www.cdc.gov/mmwr/previ ew $/ \mathrm{mmw} \mathrm{rhtml} / \mathrm{mm} 5853 \mathrm{al}$.htm. Accessed: May 23, 2011.

${ }^{12}$ Kansas Department of Health and Environment - Bureau of Epidemiology and Public Health Informatics. Unpublished data. May 2011.

${ }^{13}$ Azad H, Thomas S. West Nile encephalitis. Hosp Physician 2004; 40(5):12-16.

${ }^{14}$ Sejvar JJ, Haddad MB, Tierney BC, et al. Neurological manifestations and outcome of West Nile virus infection. JAMA 2003; 290(4):511-515. PMID: 12876094.

${ }^{15}$ Nash D, Mostashari F, Fine A. The outbreak of West Nile virus infection in the New York City area in 1999. N Engl J Med 2001; 344(24):1807-1814. PMID: 11407341 .

${ }^{16}$ Madden K. West Nile virus infection and its neurological manifestations. Clin Med Res 2003; 1(2):145-150. PMID: 1593130 2.

${ }^{17}$ Anderson JF, Rahal JJ. Efficacy of interferon $\alpha-2 b$ and ribavirin against West Nile virus in vitro. Emerg Infect Dis 2002; 8(1):107-108. PMID: 11749765.

Keywords: West Nile virus, encephalitis, flavivirus, case report 